\title{
Ethyl diazoacetate synthesis in flow
}

\author{
Mariëlle M. E. Delville, Jan C. M. van Hest and Floris P. J. T. Rutjes
}

\section{Full Research Paper}

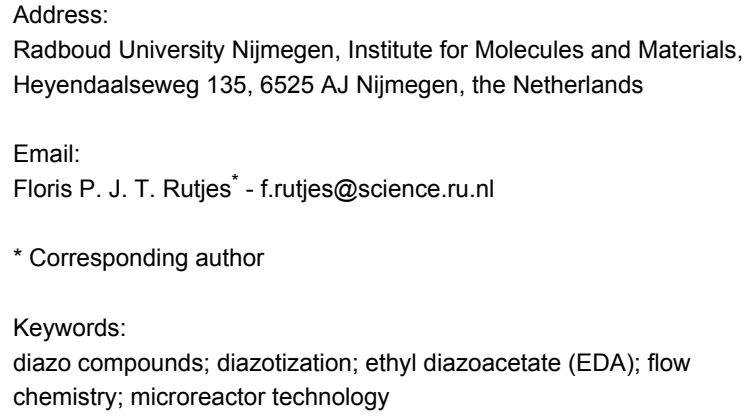

Beilstein J. Org. Chem. 2013, 9, 1813-1818. doi:10.3762/bjoc.9.211

\author{
Received: 28 June 2013 \\ Accepted: 15 August 2013 \\ Published: 05 September 2013 \\ Guest Editor: A. Kirschning \\ (C) 2013 Delville et al; licensee Beilstein-Institut. \\ License and terms: see end of document.
}

This article is part of the Thematic Series "Chemistry in flow systems III".

\begin{abstract}
Ethyl diazoacetate is a versatile compound in organic chemistry and frequently used on lab scale. Its highly explosive nature, however, severely limits its use in industrial processes. The in-line coupling of microreactor synthesis and separation technology enables the synthesis of this compound in an inherently safe manner, thereby making it available on demand in sufficient quantities. Ethyl diazoacetate was prepared in a biphasic mixture comprising an aqueous solution of glycine ethyl ester, sodium nitrite and dichloromethane. Optimization of the reaction was focused on decreasing the residence time with the smallest amount of sodium nitrite possible. With these boundary conditions, a production yield of $20 \mathrm{~g}$ EDA day ${ }^{-1}$ was achieved using a microreactor with an internal volume of $100 \mu \mathrm{L}$. Straightforward scale-up or scale-out of microreactor technology renders this method viable for industrial application.
\end{abstract}

\section{Introduction}

Diazo compounds are frequently used versatile building blocks in organic chemistry [1,2]. From this class of compounds diazomethane and ethyl diazoacetate (1, EDA) are arguably the synthetically most useful ones. Due to the potentially explosive nature of diazomethane and EDA [3-5], however, synthetic routes that involve large scale batchwise handling of such diazo compounds is generally avoided in industrial processes. With the advent of continuous processing over the past decade, new approaches have appeared to conceptually change the way chemical synthesis is performed. In particular continuous-flow microreactor technology offers multiple advantages over batch chemistry, including the inherently safe conducting of reactions due to the small reactor dimensions, efficient heat transport and excellent control over the reaction conditions [6-8]. While the synthesis of diazomethane has been extensively explored in batch [9] and in continuous-flow reactors [10,11], EDA is synthesized via different routes in batch $[12,13]$, but relatively little is known about continuous-flow approaches [14]. Considering the importance of EDA in a wide variety of reactions e.g. cyclopropanation, $\mathrm{X}-\mathrm{H}$ insertion, cycloaddition and ylide formation $[13,15]$, and more recently, in the synthesis of valuable compound classes such as $\beta$-keto esters [16] and $\beta$-hydroxy- $\alpha$ - 
diazocarbonyl compounds [17], we aimed to develop an inherently safe continuous-flow EDA process using microreactor and separation technology.

Ethyl diazoacetate (1) can be synthesized in flow via different pathways. Bartrum et al. [18] published a flow synthesis of numerous diazo esters starting from the corresponding arylsulfonylhydrazones, where the diazo moiety was installed through elimination of the sulfone substituent. Additionally, Ley et al [19] recently prepared a range of $\alpha$-hydroxy acids in flow starting from the corresponding amino acids, involving diazotization of the amine to the diazonium salt in a biphasic system. Inspired by Ley's approach, which is significantly more atom efficient than the sulfonylhydrazone pathway, we chose to synthesize EDA (1) from glycine ethyl ester (2) using readily available sodium nitrite [20] (Scheme 1). Although the diazotization step itself resembles the first step of Ley's hydroxy acid synthesis, we specifically aimed to produce and isolate the diazo product, which from there can be used for subsequent reactions.

$$
\underset{2}{\mathrm{Cl}^{\ominus}} \stackrel{\mathrm{NaNO}_{2}}{\stackrel{\mathrm{O}}{\mathrm{H}} \underbrace{\oplus}_{\mathrm{OEt}}} \underset{\mathrm{CH}_{2} \mathrm{Cl}_{2} / \text { buffer }(\mathrm{pH}=3.5)}{\mathrm{N}_{2}} \underbrace{\mathrm{O}}_{\mathrm{OEt}}
$$

Scheme 1: Synthesis of ethyl diazoacetate (1).

We intended to optimize the process focusing on decreasing the residence time in order to reduce solvent use and gain in throughput. Reaction temperature was considered less of an issue since in an industrial setting energy can generally be efficiently regenerated. In-line phase separation was thought to greatly enhance the usefulness of the EDA flow synthesis. Therefore, the outlet of the microreactor was directly connected to membrane-based phase separator to obtain EDA in the organic phase, which in principle can then be immediately used for either batch $[13,15]$ or continuous-flow [16,17] follow-up reactions. Straightforward scale-up or scale-out of microreactor technology renders this method viable for industrial application.

\section{Results and Discussion Flow synthesis}

Ethyl diazoacetate (1) was synthesized from glycine ethyl ester (2) and sodium nitrite in a biphasic system of dichloromethane and an aqueous sodium acetate buffer. Dichloromethane was chosen as the organic phase to dissolve the water insoluble EDA, because of its low water uptake and low boiling point and its compatibility with potential follow-up reactions. In principle, however, any other organic solvent immiscible with water could be used. The $\mathrm{pH}$ of the buffer was set to 3.5 which had been identified by Clark et al. as the optimal $\mathrm{pH}$ for the reaction [12]. A schematic representation of the initial microreactor set-up is shown in Figure 1. The box with the dotted line indicates the single-glass microreactor containing two mixing units $\mathrm{M}$ of the folding flow type [21]. The reactor temperature was controlled by a Peltier element and sensed by a Pt1000 temperature sensor. At the outlet of the microreactor, a back-pressure regulator (BPR, 40 psi) was attached to guarantee a liquid phase even above boiling temperatures of the solvents. To ensure welldefined reaction times during optimization experiments, neat $N, N$-diisopropylethylamine (DIPEA) was added via syringe 4 to efficiently quench the reaction. The collected product $(60 \mu \mathrm{mol})$ was analyzed by HPLC to establish the conversion of the reaction.

\section{Univariate optimization}

Determination of the optimal conditions for the reaction started off with investigating the important reaction parameters via a univariate optimization. Based on knowledge obtained from EDA synthesis in batch [12] and other flow reactions [22,23], residence time, temperature and $\mathrm{NaNO}_{2}$ stoichiometry were chosen as relevant parameters. Temperature was expected to have a large influence on the rate of the reaction. Shortening the residence time to a minimum would minimize the risk of side reactions and reduce costs, and the reaction should be

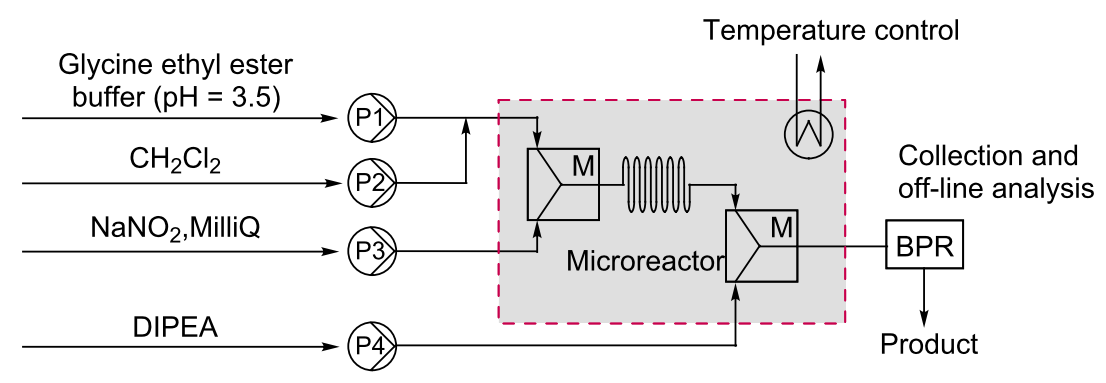

Figure 1: Schematic representation of the microreactor setup. 


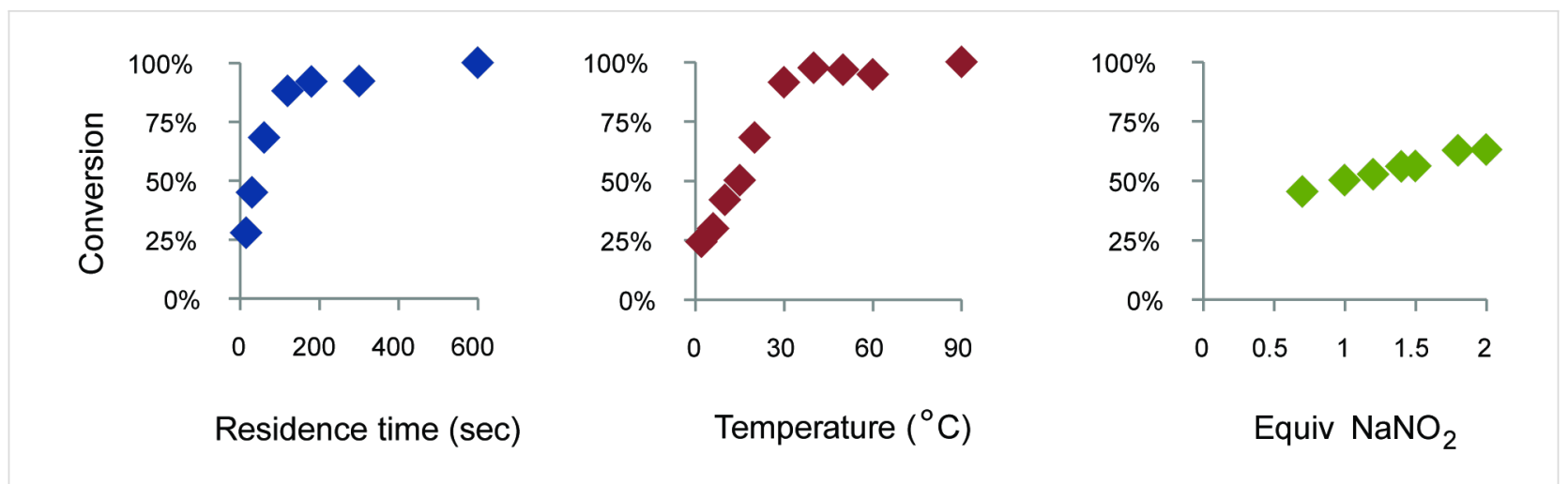

Figure 2: Univariate optimization using $30 \mathrm{~s}, 15^{\circ} \mathrm{C}$ and 1.5 equiv $\mathrm{NaNO}_{2}$ as standard.

performed with the smallest amount of $\mathrm{NaNO}_{2}$ possible. The results of the univariate optimization are shown in Figure 2. EDA synthesis was shown to be fast, since within 200 seconds complete conversion was obtained at $15{ }^{\circ} \mathrm{C}$. Additionally, the temperature shows a steep increase between $0-30{ }^{\circ} \mathrm{C}$, indicating a large influence of both parameters on the reaction rate. The amount of $\mathrm{NaNO}_{2}$ shows only a rather small influence. Based on these univariate optimizations the experimental ranges of the three parameters were determined to investigate the interrelationships via a multivariate optimization.

\section{Multivariate optimization}

An experimental design based on a D-optimal algorithm was created from the aforementioned three parameters within their respective ranges, namely $5-120 \mathrm{~s}, 0-60^{\circ} \mathrm{C}$ and $0.7-1.5$ equiv of $\mathrm{NaNO}_{2}$. Using MATLAB (MathWorks, R2007a), fifty data points were selected of which the corresponding experiments were performed in random order. The resulting HPLC yields were normalized and fitted to a third order polynomial model. In-house-developed FlowFit software [24] was used to calculate the best possible model fit. The results are visualized in 2D-contour plots (Figure 3).
These plots show a rather broad optimum for the conversion of glycine ethyl ester (2) into EDA (1). The decrease in the upper left corner of the second contour plot can be explained by the high uncertainty of the model at the edge of the plots. As was expected, temperature has a large influence on the reaction rate. The conversion into EDA shows a steep increase with increasing temperature. High temperatures and increasing amounts of $\mathrm{NaNO}_{2}$ decrease the residence time to a minimum of 20 seconds while still obtaining complete conversion. Not surprisingly, the minimal amount of $\mathrm{NaNO}_{2}$ required is 1 equivalent. We aimed to reach complete conversion into EDA (1) maintaining a short residence time with a minimum amount of sodium nitrite, possibly using higher temperatures. Based on these boundary conditions, the optimal parameter settings were fixed at 20 seconds residence time, a temperature of $50{ }^{\circ} \mathrm{C}$ using 1.5 equivalents of $\mathrm{NaNO}_{2}$. A triple-experiment was performed to prove that this set of optimal parameters indeed provided complete conversion into EDA. The experiment was performed in alternation with two other sets of parameters to rule out potential memory effects. HPLC yields of 95, 96 and 95\% for the triple-experiment demonstrate the high reproducibility of the system.

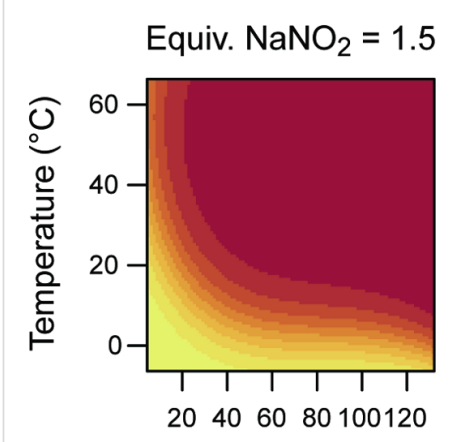

Residence time (sec)

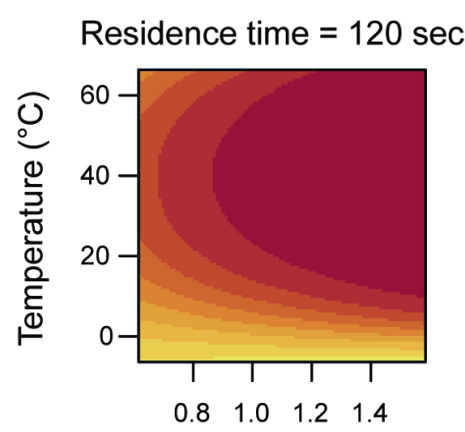

Equiv $\mathrm{NaNO}_{2}$

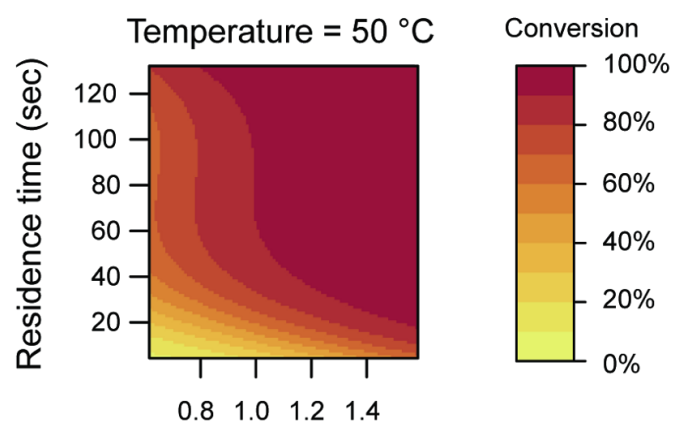

Equiv $\mathrm{NaNO}_{2}$ 


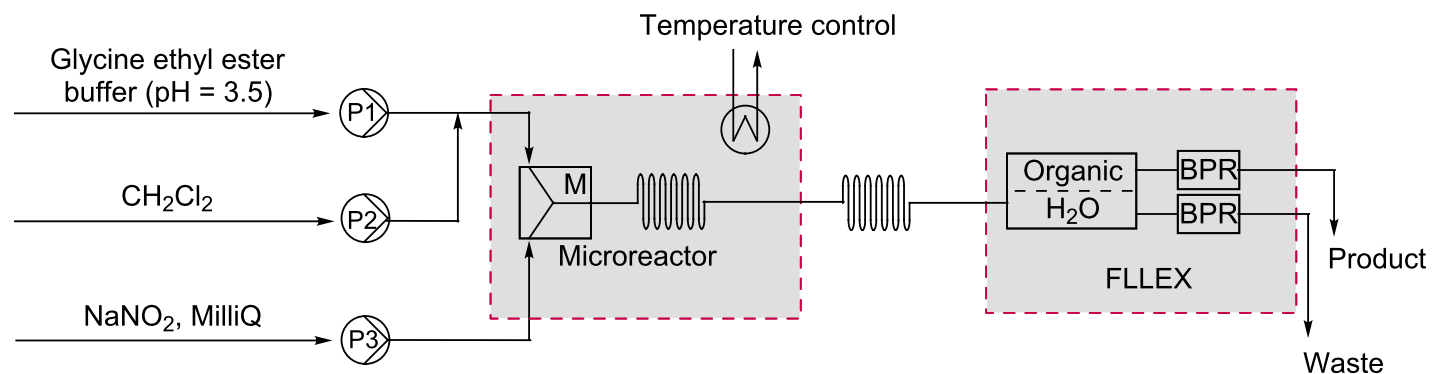

Figure 4: Phase separation using a Flow-Liquid-Liquid-Extraction module (FLLEX) directly coupled to the microreactor.

\section{FLLEX module}

Having established a microreactor protocol for the continuousflow synthesis of EDA, the next issue was to separate the product from the biphasic system in which it was collected. In order to increase safety and decrease the hold-up of EDA, the phase separation ideally had to be performed in flow as well. Therefore, a Flow-Liquid-Liquid-Extraction module (FLLEX) [25] was connected to the system [26,27]. The module utilizes a hydrophobic Teflon membrane and two back-pressure regulators (BPRs) to create a pressure difference, which causes the organic layer, in this case dichloromethane, to pass through the membrane resulting in phase separation. A schematic representation of the whole setup is shown in Figure 4.

As the conversion into EDA was quantitative, quenching with DIPEA was no longer required. Between the microreactor and the FLLEX module some additional tubing was used to ensure complete partitioning of the compounds over the two phases. The back pressure of the FLLEX was set to 40 psi, similar to the BPR used previously, and a pressure difference of 0.14 bar. Direct full separation of phases resulted in a clean organic phase containing $409 \mathrm{mg}$ EDA (11 wt \% solution in $\mathrm{CH}_{2} \mathrm{Cl}_{2}$, after 30 min of collection) while all salts remain in the aqueous phase. This corresponds roughly to an EDA production of $20 \mathrm{~g} \mathrm{day}^{-1}$ and a space time yield of $100 \mathrm{~kg} \mathrm{day}^{-1} \mathrm{dm}^{-3}$ as compared to a reported industrial scale batch process yielding EDA in $48 \mathrm{~g}$ day $^{-1} \mathrm{dm}^{-3}[12]$.

\section{Conclusion}

EDA can be safely synthesized utilizing microreactor and separation technology starting from cheap and readily available starting materials. Optimization of the reaction was aimed at reaching complete conversion into EDA within a minimized residence time using the smallest required amount of sodium nitrite, possibly applying higher temperatures. The optimal reaction conditions identified based on these criteria were a residence time of 20 seconds, a temperature of $50{ }^{\circ} \mathrm{C}$ and 1.5 equivalents of $\mathrm{NaNO}_{2}$. Repeating the EDA synthesis in flow employing the optimal reaction parameters showed complete conversion and high reproducibility of the results. Additionally, we successfully combined a plug-and-play microreactor setup with a commercially available membrane-based phase separation module to perform a direct in-line extraction of the product. Even in our small set-up (internal volume $100 \mu \mathrm{L}$ ), we were able to generate approximately $20 \mathrm{~g}$ of pure EDA per day (11 wt \% solution in $\mathrm{CH}_{2} \mathrm{Cl}_{2}$ ).

\section{Experimental}

\section{Physical and spectroscopic measurements}

NMR spectra were acquired at ambient temperature with a Bruker DMX $300 \mathrm{MHz}$ spectrometer. ${ }^{1} \mathrm{H}$ NMR spectra were referenced to TMS or to the residual solvent peak. HPLC analysis was performed using an Agilent 1120 Compact LC, C-18 column, 10\% acetonitrile in MilliQ, $254 \mathrm{~nm}$. Pyridine (internal standard) has a retention time of $1.75 \mathrm{~min}, \mathrm{EDA}$ of $9.67 \mathrm{~min}$.

\section{Chip dimensions}

Three different microchips were used during the experiments.

1. Single borosilicate glass quench microreactor with an internal volume of $92 \mu \mathrm{L}$, a channel width of $600 \mu \mathrm{m}$ and a channel depth of $500 \mu \mathrm{m}$.

2. Single borosilicate glass microreactor with an internal volume of $100 \mu \mathrm{L}$, a channel width of $600 \mu \mathrm{m}$ and a channel depth of $500 \mu \mathrm{m}$.

3. Single borosilicate glass quench microreactor with an internal volume of $1 \mu \mathrm{L}$, a channel width of $120 \mu \mathrm{m}$ and a channel depth of $50 \mu \mathrm{m}$.

\section{Univariate optimization}

Solution A: Glycine ethyl ester hydrochloride (40 mmol, $5.6 \mathrm{~g}$ ) dissolved in $20 \mathrm{~mL}$ buffer 1 . Solution B: $\mathrm{CH}_{2} \mathrm{Cl}_{2}$. Solution $\mathrm{C}$ : $\mathrm{NaNO}_{2}(60 \mathrm{mmol}, 4.1 \mathrm{~g})$ dissolved in $30 \mathrm{~mL}$ degassed MilliQ. 
Table 1: Conditions of the univariate experiments using $30 \mathrm{~s}, 15^{\circ} \mathrm{C}$ and 1.5 equiv $\mathrm{NaNO}_{2}$ as standard

$\begin{array}{llllllllll}\text { Time (s) } & 15 & 30 & 60 & 120 & 180 & 300 & 600 & 900 & 50 \\ \text { Temperature }\left({ }^{\circ} \mathrm{C}\right) & 0 & 5 & 10 & 15 & 20 & 30 & 40 & 50 & 60 \\ \text { Amount of } \mathrm{NaNO}_{2} & 0.7 & 1 & 1.2 & 1.4 & 1.5 & 1.8 & 2 & 90\end{array}$

Solution Q: Neat DIPEA. Buffer 1: Sodium acetate trihydrate $(132 \mathrm{mmol}, 18.0 \mathrm{~g})$ and pyridine $(7.5 \mathrm{~mL}$, internal standard) dissolved in $70 \mathrm{~mL}$ MilliQ. Concentrated hydrochloric acid $(37 \%, 12 \mathrm{M})$ was added until a $\mathrm{pH}$ of 3.5 was reached $(17 \mathrm{~mL})$, resulting in a buffer with a total volume of $105 \mathrm{~mL}$.

The flow rates and temperatures were set based on predetermined conditions of residence times and temperatures (Table 1). Experiments were performed in a glass microreactor with an internal volume of $92 \mu \mathrm{L}$. Solution $\mathrm{Q}$ was set at a flow rate $1 / 3$ of the flow rate of solution A. Each experiment had a collection time equal to $30 \mu \mathrm{L}$ of solution $\mathrm{A}$. The product was collected in $1 \mathrm{~mL}$ of acetonitrile and analyzed by HPLC. Results are visualized in Figure 2.

\section{Multivariate optimization}

Solution A: Glycine ethyl ester hydrochloride (40 mmol, $5.6 \mathrm{~g}$ ) dissolved in $20 \mathrm{~mL}$ buffer 1 . Solution B: $\mathrm{CH}_{2} \mathrm{Cl}_{2}$. Solution $\mathrm{C}$ : $\mathrm{NaNO}_{2}(60 \mathrm{mmol}, 4.1 \mathrm{~g})$ dissolved in $30 \mathrm{~mL}$ degassed MilliQ. Solution Q: Neat DIPEA.

The flow rates and temperatures were set based on predetermined conditions of residence times and temperatures (Table 2). Experiments with a residence time of $5 \mathrm{~s}$ were performed in a glass microreactor with an internal volume of $1 \mu \mathrm{L}$. For longer residence times, a microreactor with an internal volume of $92 \mu \mathrm{L}$ was used. Solution Q was set at a flow rate $1 / 3$ of the flow rate of solution A. Each experiment had a collection time equal to $30 \mu \mathrm{L}$ of solution $\mathrm{A}$. The product was collected in

Table 2: Experiments for the multivariate optimization deduced from a D-optimal experimental design algorithm.

\begin{tabular}{|c|c|c|c|c|c|c|c|}
\hline Exp\# & Molar ratio & Residence time (s) & Temperature $\left({ }^{\circ} \mathrm{C}\right)$ & Exp\# & Molar ratio & Residence time (s) & Temperature $\left({ }^{\circ} \mathrm{C}\right)$ \\
\hline 1 & 1.5 & 5 & 0 & 26 & 1.1 & 120 & 0 \\
\hline 2 & 1.5 & 120 & 60 & 27 & 1.5 & 120 & 60 \\
\hline 3 & 1.5 & 45 & 0 & 28 & 0.7 & 5 & 0 \\
\hline 4 & 0.7 & 5 & 60 & 29 & 1.1 & 15 & 60 \\
\hline 5 & 1.5 & 45 & 60 & 30 & 1.1 & 120 & 60 \\
\hline 6 & 1.5 & 120 & 40 & 31 & 1.1 & 45 & 60 \\
\hline 7 & 1.5 & 45 & 0 & 32 & 1.5 & 5 & 20 \\
\hline 8 & 0.7 & 45 & 0 & 33 & 1.5 & 120 & 20 \\
\hline 9 & 1.5 & 15 & 20 & 34 & 0.7 & 15 & 0 \\
\hline 10 & 1.1 & 5 & 20 & 35 & 0.7 & 5 & 20 \\
\hline 11 & 0.7 & 45 & 20 & 36 & 1.1 & 5 & 60 \\
\hline 12 & 1.5 & 120 & 0 & 37 & 1.5 & 15 & 60 \\
\hline 13 & 1.1 & 15 & 0 & 38 & 0.7 & 45 & 60 \\
\hline 14 & 0.7 & 5 & 60 & 39 & 1.1 & 120 & 60 \\
\hline 15 & 0.7 & 120 & 40 & 40 & 1.1 & 120 & 40 \\
\hline 16 & 0.7 & 45 & 60 & 41 & 1.1 & 5 & 40 \\
\hline 17 & 1.5 & 120 & 0 & 42 & 0.7 & 5 & 40 \\
\hline 18 & 1.5 & 5 & 60 & 43 & 1.1 & 5 & 0 \\
\hline 19 & 1.5 & 45 & 40 & 44 & 0.7 & 120 & 60 \\
\hline 20 & 0.7 & 120 & 60 & 45 & 1.1 & 120 & 0 \\
\hline 21 & 1.5 & 5 & 0 & 46 & 0.7 & 15 & 40 \\
\hline 22 & 1.5 & 5 & 60 & 47 & 0.7 & 5 & 0 \\
\hline 23 & 1.1 & 45 & 0 & 48 & 0.7 & 120 & 0 \\
\hline 24 & 1.1 & 120 & 20 & 49 & 0.7 & 120 & 20 \\
\hline 25 & 1.5 & 5 & 40 & 50 & 0.7 & 120 & 0 \\
\hline
\end{tabular}


$1 \mathrm{~mL}$ of acetonitrile and analyzed by HPLC. Results are visualized in Figure 3 as 2D-contour plots.

\section{FLLEX experiment}

Solution A: Glycine ethyl ester hydrochloride (10 mmol, $1.4 \mathrm{~g})$ dissolved in $5 \mathrm{~mL}$ buffer 2. Solution B: $\mathrm{CH}_{2} \mathrm{Cl}_{2}$. Solution $\mathrm{C}$ : $\mathrm{NaNO}_{2}(15 \mathrm{mmol}, 1.0 \mathrm{~g})$ dissolved in $5 \mathrm{~mL}$ degassed MilliQ. Buffer 2: Sodium acetate trihydrate (100 mmol $13.6 \mathrm{~g})$ dissolved in $80 \mathrm{~mL}$ MilliQ. Concentrated hydrochloric acid $(37 \%, 12 \mathrm{M})$ was added until a $\mathrm{pH}$ of 3.5 was reached $(7 \mathrm{~mL})$. Additional MilliQ was added to obtain a total volume of $100 \mathrm{~mL}$ of buffer.

Solution A $(86.25 \mu \mathrm{L} / \mathrm{min})$ was combined in a stainless steel T-splitter with solution B (172.5 $\mu \mathrm{L} / \mathrm{min})$. The biphasic mixture immediately entered the glass microreactor (internal volume: $100 \mu \mathrm{L})$ where it was mixed with solution $\mathrm{C}(86.25 \mu \mathrm{L} / \mathrm{min})$. The reaction was performed at $50{ }^{\circ} \mathrm{C}$. After the reaction, the mixture was passed through $15 \mu \mathrm{L}$ of FEP-tubing (ID = $254 \mu \mathrm{m}$ ) before entering the FLLEX module where phases were separated ( $40 \mathrm{psi}, \Delta p=0.14$ bar). The set-up was stabilized for $2 \mathrm{~min}$ before collecting for $30 \mathrm{~min}$. EDA was obtained as a solution in $\mathrm{CH}_{2} \mathrm{Cl}_{2}(1.52 \mathrm{~g})$. According to ${ }^{1} \mathrm{H}$ NMR analysis, clean EDA was obtained. Based on the residual solvent peak in the ${ }^{1} \mathrm{H}$ NMR spectrum it was calculated to be a $27 \mathrm{wt} \%$ solution of EDA in $\mathrm{CH}_{2} \mathrm{Cl}_{2}$ meaning $409 \mathrm{mg}$ of pure EDA.

\section{Acknowledgements}

We thank Dr. Pieter Nieuwland (FutureChemistry) for fruitful discussions. The NWO-ACTS Process-on-a-Chip (PoaC) program is kindly acknowledged for financial support.

\section{References}

1. Regitz, M. Synthesis 1972, 351-373. doi:10.1055/s-1972-21883

2. Zhang, Z.; Wang, J. Tetrahedron 2008, 64, 6577-6605. doi:10.1016/j.tet.2008.04.074

3. Clark, J. D.; Shah, A. S.; Peterson, J. C.; Patelis, L.; Kersten, R. J. A.; Heemskerk, A. H.; Grogan, M.; Camden, S. Thermochim. Acta 2002, 386, 65-72. doi:10.1016/S0040-6031(01)00760-2

4. Clark, J. D.; Shah, A. S.; Peterson, J. C.; Patelis, L.; Kersten, R. J. A.; Heemskerk, A. H. Thermochim. Acta 2002, 386, 73-79. doi:10.1016/S0040-6031(01)00761-4

5. Hosmane, R. S.; Liebman, J. F. Struct. Chem. 2002, 13, 501-503. doi:10.1023/A:1020573723147

6. Wegner, J.; Ceylan, S.; Kirschning, A. Adv. Synth. Catal. 2012, 354, 17-57. doi:10.1002/adsc.201100584

7. Wiles, C.; Watts, P. Chem. Commun. 2011, 47, 6512-6535. doi:10.1039/c1cc00089f

8. Wirth, T., Ed. Microreactors in Organic Synthesis and Catalysis; Wiley-VCH: Weinheim, Germany, 2008. doi:10.1002/9783527622856

9. Cohen, J. D. J. Chromatogr. 1984, 303, 193-196. doi:10.1016/S0021-9673(01)96061-3

10. Ferstl, W. F.; Schwarzer, S.; Loebbecke, S. L. Chem. Ing. Tech. 2004, 76, 1326-1327. doi:10.1002/cite.200490233
11. Struempel, M.; Ondruschka, B.; Duate, R.; Stark, A. Green Chem. 2008, 10, 41-43. doi:10.1039/b710554a

12. Clark, J. D.; Heise, J. D.; Shah, A. S.; Peterson, J. C.; Chou, S. K.; Levine, J.; Karakas, A. M.; Ma, Y.; Ng, K.-Y.; Patelis, L.; Springer, J. R.; Stano, D. R.; Wettach, R. H.; Dutra, G. A. Org. Process Res. Dev. 2004, 8, 176-185. doi:10.1021/op034123q

13. Maas, G. Angew. Chem., Int. Ed. 2009, 48, 8186-8195. doi:10.1002/anie.200902785

14. Thathagar, M.; Poechlauer, P.; Braune, S. Process for the production of cyclopropane derivatives. WO2010055106, May 20, 2010.

15. Davies, H. M. L.; Beckwith, R. E. J. Chem. Rev. 2003, 103, 2861-2903. doi:10.1021/cr0200217

16. Bartum, H. E.; Blakemore, D. C.; Moody, C. J.; Hayes, C. J. J. Org. Chem. 2010, 75, 8674-8676. doi:10.1021/jo101783m

17. Krishna, P. R.; Prapurna, Y. L.; Alivelu, M. Eur. J. Org. Chem. 2011, 5089-5095. doi:10.1002/ejoc.201100496

18. Bartrum, H. E.; Blakemore, D. C.; Moody, C. J.; Hayes, C. J. Chem.-Eur. J. 2011, 17, 9586-9589. doi:10.1002/chem.201101590

19. Hu, D. X.; O'Brien, M.; Ley, S. V. Org. Lett. 2012, 14, 4246-4249. doi:10.1021/ol301930h

20. Monbaliu, J. C.; Jorda, J.; Chevalier, B.; Stevens, C. V.; Morvan, B. Chim. Oggi 2011, 29, 50-52.

See for the use of sodium nitrite in flow chemistry for example.

21. MacInnes, J. M.; Vikhansky, A.; Allen, R. K. W. Chem. Eng. Sci. 2007, 62, 2718-2727. doi:10.1016/j.ces.2007.02.014

22. Delville, M. M. E.; Nieuwland, P. J.; Janssen, P.; Koch, K.; van Hest, J. C. M.; Rutjes, F. P. J. T. Chem. Eng. J. 2011, 167, 556-559. doi:10.1016/j.cej.2010.08.087

23. Delville, M. M. E.; van Gool, J. J. F.; van Wijk, I. M.; van Hest, J. C. M.; Rutjes, F. P. J. T. J. Flow Chem. 2012, 4, 124-128. doi:10.1556/JFC-D-12-00008

24. For more information about FlowFit software see: http://www.futurechemistry.com

25. http://www.syrris.com.

26. Tricotet, T.; O'Shea, D. F. Chem.-Eur. J. 2010, 16, 6678-6686. doi:10.1002/chem.200903284

27. Varas, A. C.; Noël, T.; Wang, Q.; Hessel, V. ChemSusChem 2012, 5, 1703-1707. doi:10.1002/cssc.201200323

\section{License and Terms}

This is an Open Access article under the terms of the Creative Commons Attribution License (http://creativecommons.org/licenses/by/2.0), which permits unrestricted use, distribution, and reproduction in any medium, provided the original work is properly cited.

The license is subject to the Beilstein Journal of Organic Chemistry terms and conditions: (http://www.beilstein-journals.org/bjoc)

The definitive version of this article is the electronic one which can be found at: doi:10.3762/bjoc.9.211 